University of Nebraska - Lincoln

DigitalCommons@University of Nebraska - Lincoln

2005

\title{
Objective Threshold Determination for Nighttime Eddy Flux
}

\section{Filtering}

Lianhong $\mathrm{Gu}$

Oak Ridge National Laboratory, Oak Ridge, TN

Eva M. Falge

Plant Ecology, Bayreuth University, Bayreuth, Germany

Tom Boden

Oak Ridge National Laboratory, Oak Ridge, TN

Dennis D. Baldocchi

University of California, Berkeley, baldocchi@berkeley.edu

T.A. Black

Faculty of Agricultural Sciences, University of British Columbia, Vancouver, Canada

See next page for additional authors

Follow this and additional works at: https://digitalcommons.unl.edu/natrespapers

Part of the Natural Resources and Conservation Commons

Gu, Lianhong; Falge, Eva M.; Boden, Tom; Baldocchi, Dennis D.; Black, T.A.; Saleska, Scott R.; Suni, Tanja; Verma, Shashi; Vesala, Timo; Wofsy, Steve C.; and Xu, Liukang, "Objective Threshold Determination for Nighttime Eddy Flux Filtering" (2005). Papers in Natural Resources. 151.

https://digitalcommons.unl.edu/natrespapers/151

This Article is brought to you for free and open access by the Natural Resources, School of at DigitalCommons@University of Nebraska - Lincoln. It has been accepted for inclusion in Papers in Natural Resources by an authorized administrator of DigitalCommons@University of Nebraska - Lincoln. 


\section{Authors}

Lianhong Gu, Eva M. Falge, Tom Boden, Dennis D. Baldocchi, T.A. Black, Scott R. Saleska, Tanja Suni, Shashi Verma, Timo Vesala, Steve C. Wofsy, and Liukang Xu 


\title{
Objective threshold determination for nighttime eddy flux filtering
}

\author{
Lianhong $\mathrm{Gu}^{\mathrm{a}}{ }^{*}$, Eva M. Falge ${ }^{\mathrm{b}}$, Tom Boden ${ }^{\mathrm{a}}$, Dennis D. Baldocchi ${ }^{\mathrm{c}}$, \\ T.A. Black ${ }^{\mathrm{d}}$, Scott R. Saleska ${ }^{\mathrm{e}}$, Tanja Suni ${ }^{\mathrm{f}}$, Shashi B. Verma ${ }^{\mathrm{g}}$, \\ Timo Vesala ${ }^{\mathrm{f}}$, Steve C. Wofsy ${ }^{\mathrm{e}}$, Liukang $\mathrm{Xu}^{\mathrm{c}}$ \\ a Environmental Sciences Division, Building 1509, Mail Stop 6335, Oak Ridge National Laboratory, Oak Ridge, TN 37831-6335, USA \\ ${ }^{\mathrm{b}}$ Plant Ecology, Bayreuth University, Bayreuth, Germany \\ ${ }^{\mathrm{c}}$ Department of Environmental Sciences, Policy, and Management, University of California, Berkeley, USA \\ ${ }^{\mathrm{d}}$ Faculty of Agricultural Sciences, University of British Columbia, Vancouver, Canada \\ ${ }^{\mathrm{e}}$ Division of Engineering and Applied Science and Department of Earth and Planetary Sciences, \\ Harvard University, Cambridge, MA, USA \\ ${ }^{\mathrm{f}}$ Department of Physical Sciences, University of Helsinki, Helsinki, Finland \\ ${ }^{\mathrm{g}}$ School of Natural Resources, University of Nebraska, Lincoln, USA
}

Received 15 June 2004; accepted 10 November 2004

\begin{abstract}
We recommend an automated statistical method (Moving Point Test, or MPT) to determine the friction velocity $\left(u_{*}\right)$ thresholds in nighttime eddy flux filtering. Our intention is to make the determination of the $u_{*}$ thresholds objective and reproducible and to keep flux treatment consistent over time and across sites. In developing the MPT method, we recognize that both ecosystem respiration and $u_{*}$ exhibit diurnal and seasonal cycles and there are potential correlative changes between them, which must be removed before $u_{*}$ can be used as a filter criterion. MPT uses an iterative approach to simultaneously determine a valid temperature response function, which is used to normalize nighttime flux measurements, and identify $u *$ thresholds based on the normalized fluxes. Tests show that MPT works well for a variety of scenarios and vegetation types. We also recommend that in order to increase the reliability of nighttime flux filters, a detailed measurement of mean $\mathrm{CO}_{2}$ concentration profiles need to be employed to calculate canopy storage changes accurately. Preferably, multiple profiles at different locations within the nighttime flux footprint should be used so that volume-averaged storage changes can be made. In addition, efforts should be made to minimize measurement gaps in summer nights as much as possible because of the short-time duration and frequent calm conditions, which greatly limit the amount of reliable data. We emphasize that the MPT method is not meant to be a final solution to the nighttime flux issue. Continuous theoretical and experimental researches are still needed to overcome the challenges in measuring nighttime fluxes accurately.
\end{abstract}

Keywords: Eddy covariance; Turbulence; Friction velocity; Net ecosystem exchange; Fluxes; Moving point test

\footnotetext{
* Corresponding author. Tel.: +1 865241 5925; fax: +1 8655742232.

E-mail address: lianhong-gu@ornl.gov (L. Gu).
} 


\section{Introduction}

The flux community has recognized that the eddy covariance technique often underestimates nighttime net ecosystem exchanges (NEE) of $\mathrm{CO}_{2}$ under stably stratified atmospheric conditions (e.g. Goulden et al., 1996; Jarvis et al., 1997; Black et al., 2000; Valentini et al., 2000). Causes of this phenomenon and the theoretical framework for its correction are still under active investigation (Lee, 1998; Finnigan, 1999; Baldocchi et al., 2000; Massman and Lee, 2002). For a practical solution, many researchers filter their nighttime measurements based on atmospheric turbulence conditions using friction velocity $\left(u_{*}\right)$ as an indicator. The screened dataset is then used to develop a temperature response function to fill the gaps created as a result of the filtering process.

The underlying assumption of this procedure is that the nighttime NEE is biologically determined and thus should be independent of turbulence regimes (Wofsy et al., 1993; Goulden et al., 1996; Massman and Lee, 2002). The implementation of this filtering approach entails the determination of the so-called $u *$ threshold below which low turbulence is deemed to affect the flux measured by the eddy covariance system. In general, measured $\mathrm{CO}_{2}$ flux becomes negligible as $u_{*}$ decreases to zero (Massman and Lee, 2002). Thus the use of a $u *$ filter tends to increase the estimated annual ecosystem respiration and decrease the estimated annual net uptake of $\mathrm{CO}_{2}$ by the ecosystem (Goulden et al., 1996; Aubinet et al., 2000; Barr et al., 2002; Saleska et al., 2003). Barford et al. (2001) showed smaller net annual carbon uptake with the application of higher $u_{*}$ thresholds, although the decreasing trend diminishes as the $u *$ threshold increases. Massman and Lee (2002) surveyed the literature and found that $u_{*}$ thresholds used at different sites ranged from 0.0 to $0.6 \mathrm{~ms}^{-1}$.

At present, there is no commonly accepted method to determine the $u_{*}$ threshold. In the literature, researchers often find the $u_{*}$ threshold by visually examining the scatter plot of nighttime fluxes versus $u_{*}$. Conceptually, it is assumed that the threshold is located where the flux begins to level off as $u_{*}$ increases. This approach is subject to criticism due to the absence of any standard. On the one hand, fluxes measured during nighttime often appear to be rather noisy in the NEE $-u *$ scatter plot, particularly when the observed range of $u_{*}$ is limited, as frequently is the case during nighttime. It is common that no clear patterns can be recognized visually. Even when there are easily identifiable patterns, finding a $u_{*}$ threshold depends on individual researchers' judgment and different researchers may come to different thresholds from the same data set. This practice introduces human discrepancies for individual sites when investigators change and must be considered when different sites are compared. On the other hand, there is no basis to think that the $u_{*}$ threshold is constant over time and space. It may well depend on leaf area distribution, stem density, canopy height, as well as meteorological conditions and terrain characteristics. Consequently, employing a single $u *$ threshold all the time or across different sites may also introduce biases. These potential problems associated with the visual examination approach have the danger of rendering the $u_{*}$ threshold a free-tuning parameter for eddy covariance measurements, thus jeopardizing data integrity and causing uncertainties in annual estimates of net ecosystem production (NEP). This may have considerable consequences in our evaluation of carbon source and sink distributions over space and time since annual net carbon uptake is the small difference between two large numbers (photosynthesis and ecosystem respiration).

As the length of eddy flux measurement records at existing sites grows and new sites are being rapidly added to flux networks around the world (Baldocchi et al., 2001), consistent treatment of flux datasets across time and space becomes increasingly important. A more objective, yet still practical method, is clearly needed to replace the subjective use of the $u_{*}$ filter. The FLUXNET project office has been using an iterative method in processing nighttime flux data compiled by the project (E. Falge, personal communication). However, this method has not been documented in the peer-reviewed literature. Recently, Saleska et al. (2003) designed a statistical approach to determine $u_{*}$ thresholds. In their approach, nighttime NEE measurements are grouped into deciles based on their $u_{*}$ values. The mean $u_{*}$ of the decile that separates the high- $u_{*}$ deciles with statistically identical NEE means from the low- $u_{*}$ deciles with significantly smaller NEE means is taken as the $u_{*}$ threshold. 
In this paper, we expand the FLUXNET unpublished method and the work of Saleska et al. (2003) and develop a more complete procedure for an objective application of the $u_{*}$ filter. The new algorithm, which we call the moving point test (MPT), is a reproducible, site-independent, statistically based approach that can be automated for processing large datasets. MPT works well for a broad range of observed nighttime flux versus $u_{*}$ relationships. When employed on a network basis, it provides a potential of uniformity across different eddy covariance flux sites and over time in dealing with the nighttime flux issue. In the following, we first discuss the rationale behind the design of the MPT. We then introduce the method and later provide scenario and actual case demonstrations using measurements from a variety of vegetation types.

\section{Some general considerations on the relationship between nighttime NEE and $u_{*}$}

\subsection{Potential correlative variations in nighttime flux and $u *$}

Friction velocity has clear diurnal and seasonal cycles. Figs. 1 and 2 demonstrate these cyclic patterns for a tallgrass prairie site in Oklahoma, USA (Suyker and Verma, 2001), a mixed hardwood forest in Massachusetts, USA (Harvard Forest, Wofsy et al., 1993), and a Scots pine forest in Finland (Vesala et al., 1998). In general, diurnal variations in $u_{*}$ tend to synchronize with diurnal variations in temperature, particularly air temperature (Fig. 1). $u_{*}$ is higher during daytime and lower during nighttime. Since ecosystem respiration is strongly influenced by temperature, ecosystem respiration also exhibits diurnal cycles. Therefore ecosystem respiration and $u *$ are potentially positively correlated at diurnal time scales even though there may be no causal relationship between them. Interestingly, nighttime $u_{*}$ is out of phase with temperature and ecosystem respiration at seasonal time scales with lower $u_{*}$ in summer and higher $u_{*}$ in winter (Fig. 2, only nighttime values are included). Therefore, we may expect a negative correlation between ecosystem respiration and $u_{*}$ at seasonal time scales.

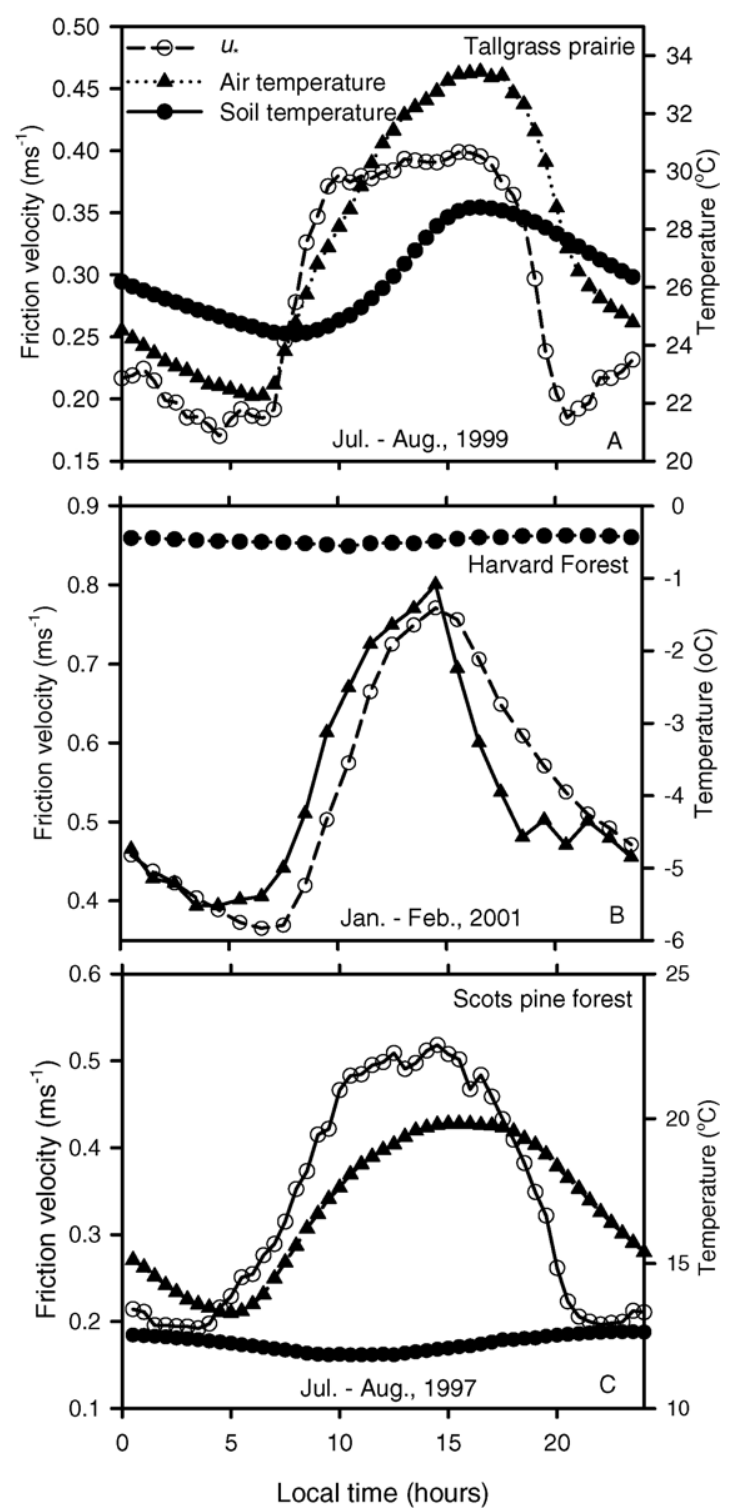

Fig. 1. Mean diurnal patterns of $u_{*}$, air temperature, and surface soil temperature in selected seasons at the tallgrass prairie site (A), the Harvard Forest site (B), and the Scots pine forest site (C) to illustrate near in-phase co-variations between $u *$ and temperature. At all sites, $u_{*}$ and air temperature were measured above the canopy, and surface soil temperature was measured at a depth of about $5 \mathrm{~cm}$.

There are two implications from these potential correlations for the use of $u_{*}$ as a criterion to screen nighttime eddy flux measurements (in this study nighttime is defined as when the Sun is below the horizon, i.e. solar elevation angle is less than zero). 

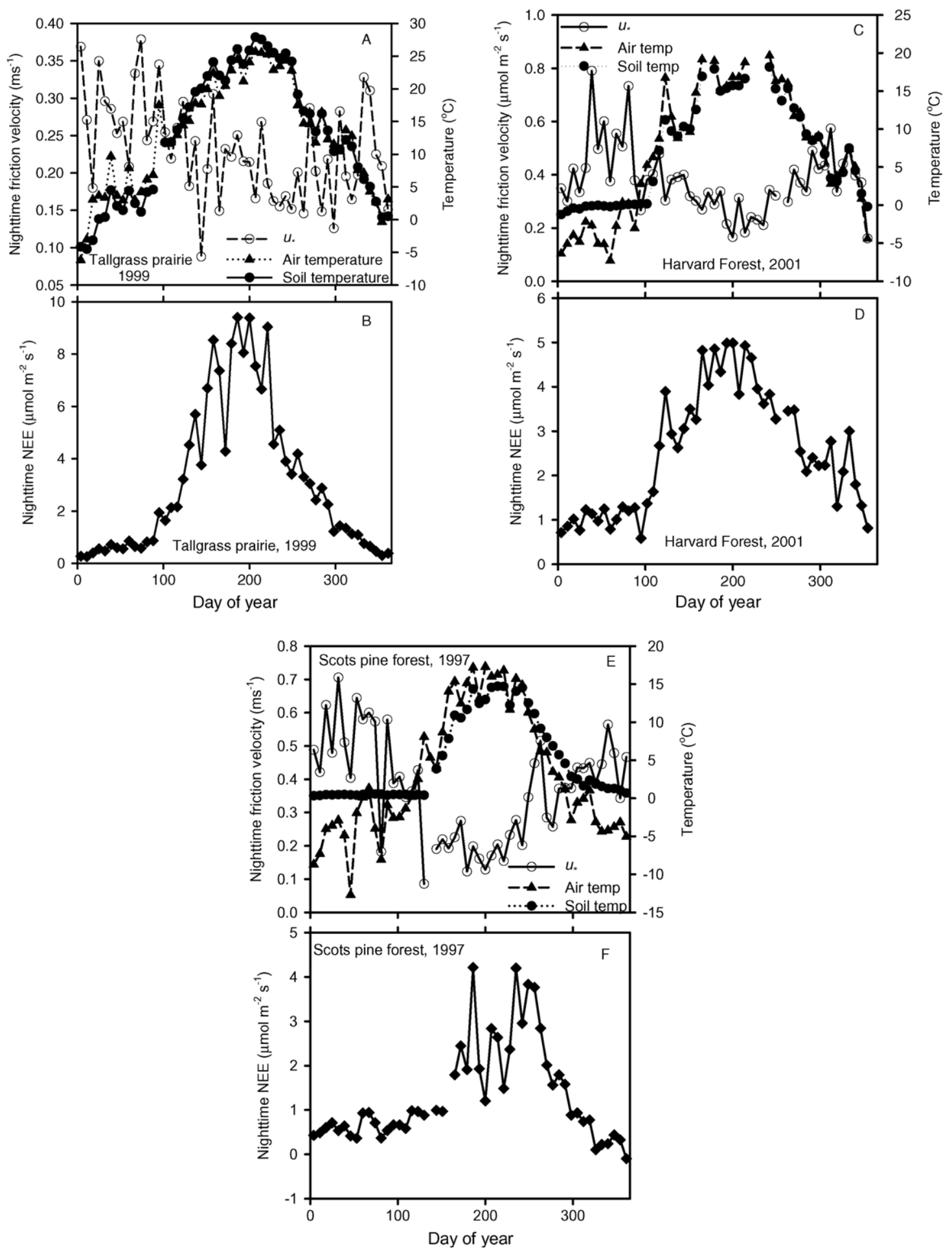

Fig. 2. Seasonal patterns in weekly nighttime mean $u_{*}$, air temperature, surface soil temperature, and NEE at the tallgrass prairie site (A and B), the Harvard Forest site (C and D), and the Scots pine forest site (E and F) to illustrate near out-phase co-variations between $u *$, temperature, and ecosystem respiration. 
First, the $u_{*}$ threshold should not be determined directly from the patterns shown in the scatter plots of nighttime NEE against $u_{*}$. The correlation between NEE and $u_{*}$ caused by their in-phase relationship at the diurnal and out-of-phase relationship at the seasonal time scales needs to be removed before a $u *$ threshold is sought. Goulden et al. (1996) and Aubinet et al. (2000) also made similar suggestions. Second, the time period used to establish the scatter pattern between the processed

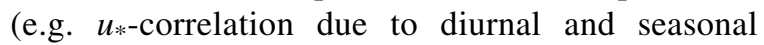
variations removed) flux and $u^{*}$ should not be too long. Otherwise, the filtering procedure can be biased against measurements obtained under particular temperature regimes, which are correlated with soil carbon pool dynamics (Gu et al., 2004), thus leading to distortion in the representation of nighttime flux measurements. For example, measurements made during summer nights could be preferentially filtered out if data from the whole year are pooled together and a single $u_{*}$ threshold is used. This, coupled with shorter nights in summer, as compared with nights in other seasons, could make estimation of summertime ecosystem respiration unreliable. Furthermore, because ecosystem respiration rates are higher and $u_{*}$ values tend to be smaller during summer nights, patterns that reveal influences of low turbulence may be obscured and become less recognizable when the scatter plots are examined on an annual basis.

\subsection{Pressure pumping effect}

Another issue we should consider is the effect of pressure pumping on soil efflux. The study conducted by Rogie et al. (2001) in Mammoth Mountain (a dormant volcano located in Sierra Nevada, California, USA) on the degassing of $\mathrm{CO}_{2}$ from underground magmatic reservoirs showed that atmospheric pressure fluctuations had strong impact on air exchange near the soil surface. These researchers found correlated, coherent structures in the time series of $\mathrm{CO}_{2}$ efflux, atmospheric pressure, and wind speed. While soil efflux derived from autotrophic and heterotrophic respirations (on the order of a few $\mu \mathrm{mol} \mathrm{m}{ }^{-2} \mathrm{~s}^{-1}$ ) is much smaller than the emission of $\mathrm{CO}_{2}$ from magmatic sources (hundreds to thousands $\left.\mu \mathrm{mol} \mathrm{m} \mathrm{m}^{-2} \mathrm{~s}^{-1}\right), \mathrm{CO}_{2}$ concentration in pores near the soil surface is much higher than concentrations of the free atmosphere (e.g. Tang et al., 2003). Therefore, air movement into and out of the soil induced by pressure fluctuations may still be able to introduce a significant physical component to the soil efflux (in addition to the biological component), particularly if the ground is covered by snow (Massman et al., 1997; Massman and Lee, 2002). This suggestion is supported by measurements from a snow-covered boreal aspen forest in the winter (JD 350-352) of 1996 during strong winds (Black et al., 2000) when a very tight exponential relationship was observed between nighttime NEE and $u_{*}$ (Fig. 3). Harazono et al. (2000) observed a similar pattern at an arctic tundra site in the winter during a blizzard. This relationship is in sharp contrast to the usual 'messy' pattern observed in the scatter plot of NEE versus $u_{*}$ under most nighttime conditions. The tightness is likely caused by pressure pumping effects under extremely turbulent conditions and the presence of a relatively large reservoir of $\mathrm{CO}_{2}$ built up over a period of time under snow cover. However, we cannot eliminate the possibility that other unknown factors may also play a role.

While dramatic patterns such as the one shown in Fig. 3 might not be common, it is desirable for a generic nighttime flux filter to have the capability to determine if pressure pumping effect exists and if

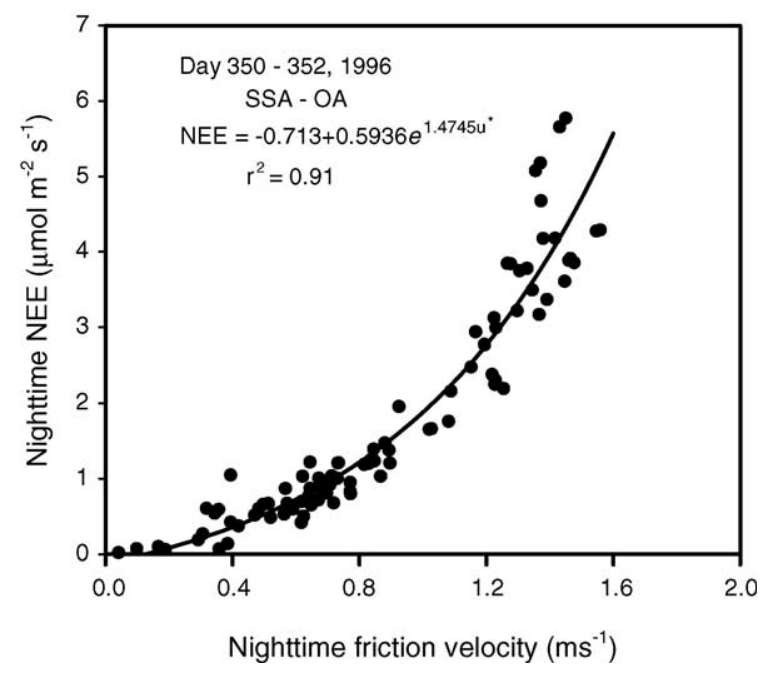

Fig. 3. Relationship between nighttime NEE and $u_{*}$ observed over three days during the winter of 1996 at the aspen forest site in Canada. Snow-covered the ground. 
fluxes are unusually large when $u_{*}$ is very high. We assume that pressure pumping effect is the primary factor in influencing the flux $-u_{*}$ relationship at the high end of $u_{*}$ with the acknowledgement that this assumption may be an oversimplification of the reality. Later we will show that there are cases in which nighttime NEE tends to increase with $u_{*}$ at both the low and high ends of the observed $u_{*}$ range. In these cases, one may consider that the eddy covariance system measures "biological fluxes" at some intermediate levels of $u_{*}$. If one filters out only measurements affected by low turbulence and uses the remaining data to develop a temperature response function to fill the resulting data gaps, the temperature response function may overestimate nighttime fluxes because of non-biological contributions to the observed fluxes affected by pressure pumping effects.

The desire to screen nighttime flux measurements for potential influences of unusually high turbulence conditions, in addition to distortions caused by lack of turbulence, reflects a consideration that the task of practical nighttime flux treatment may better be described as selecting representative 'biological fluxes' rather than as filtering out measurements affected by turbulence regimes. With this consideration, a conservative strategy placing more weight on the 'cleanliness' of the biological flux samples is preferred, although one also has to make sure that the retained samples are sufficient and representative. In this way, robust temperature response functions can be developed and used to fill gaps created in measurement records following the filtering process. This is the guiding principle in designing our filtering approach.

\subsection{Canopy storage}

Averaged over long-time intervals ( $>$ days), change in canopy storage of $\mathrm{CO}_{2}$ may be small. However, for developing temperature response functions for ecosystem respiration, measurements at short-time scales should be used because of the non-linear dependence of respiration on temperature and because of rapid labile carbon pool dynamics (Gu et al., 2004). The $u_{*}$ filter applies to the hourly or half-hourly measurements; at this time step, change in canopy storage can be significant. Therefore, the application assumes that the canopy storage change has been adequately accounted for as part of the NEE determination. Massman and Lee (2002) pointed out that the turbulent flux alone, as calculated from the Reynolds averaging of the product of fluctuations in $\mathrm{CO}_{2}$ concentration and vertical velocity, is proportional to $u_{*}$, according to both the gradient diffusion theory and the Monin-Obukhov similarity theory. Furthermore, $\mathrm{CO}_{2}$ accumulated inside the canopy under calm conditions may be flushed out and reported by the system at a later time when turbulence intensity increases (see also Grace et al., 1995; Aubinet et al., 2000). These two factors both lead to an increasing trend of eddy fluxes with $u_{*}$. Thus, if the canopy storage change is not added to the eddy flux, $u_{*}$ thresholds may be incorrectly determined and double counting of fluxes can occur. Later we will demonstrate this point using actual measurements. Throughout the paper, when we mention "NEE" or "flux", it is always assumed that the canopy storage change has been considered, unless stated otherwise.

\section{Moving point test (MPT): an iterative approach}

The above deliberation forms the basis of our conceptual model about the relationship between nighttime fluxes and $u_{*}$. In this conceptual model, nighttime fluxes are independent of $u_{*}$ over some intermediate range of $u *$ but increase with $u_{*}$ at both low and high ends of $u_{*}$. The objective of a filtering algorithm is to determine where this intermediate range starts and where it ends. The algorithm should have the flexibility to deal with different situations, for example, the intermediate range may start at $u_{*}=0 \mathrm{~ms}^{-1}$ and ends at an infinite $u_{*}$ (thus no filtering is needed) or the range may not exist at all (i.e. $u *$ cannot be used as a filter). We have designed an automated statistical method with this conceptual model in mind. The method searches simultaneously for a lower $u_{*}$ threshold $\left(u_{*_{\mathrm{L}}}\right)$, below which fluxes are potentially underestimated, and for a higher $u_{*}$ threshold $\left(u *_{\mathrm{H}}\right)$, above which measurements are subject to potential pressure pumping effects. $u_{*} \mathrm{~L}$ is found by testing a group of points with consecutive $u_{*}$ values in a narrow moving window against a reference sample (details follow). The moving window is shifted point by point in the direction from low to high $u * u * \mathrm{H}$ is determined in a similar fashion but the moving 
window is shifted from high to low $u_{*}$ values. For this reason, the method is called the moving point test (MPT).

The MPT method requires the use of a valid temperature response function to normalize nighttime flux data to remove potential correlation between ecosystem respiration and $u_{*}$ caused by their diurnal and seasonal cycles. It also needs to establish reference samples so that abnormally small or high fluxes can be detected. These two requirements pose a dilemma because we have no a priori knowledge about which data represent biological fluxes. To solve this problem, MPT employs an iterative procedure with two nested loops. The outer loop determines the temperature response function and the inner loop determines the reference sample.
We also assume that data with high $u_{*}$ values during nights otherwise dominated by low turbulence conditions are less reliable than those with similar $u_{*}$ values but from nights with relatively intensive overall turbulence conditions. This assumption stems from the consideration that persistence of calm conditions at the observation site during nighttime may indicate low large-scale wind speeds, which are conducive to the formation of drainage flows. Once drainage flow forms, air inside the canopy can be decoupled from air above the canopy and the $u *$ filter may not be applicable. However, more studies are needed and we take this assumption only as a precautious measure. With this assumption, MPT iteratively scrutinizes nights dominated by low turbulence conditions based on their median $u_{*}$ values and excludes these nights from the determination of

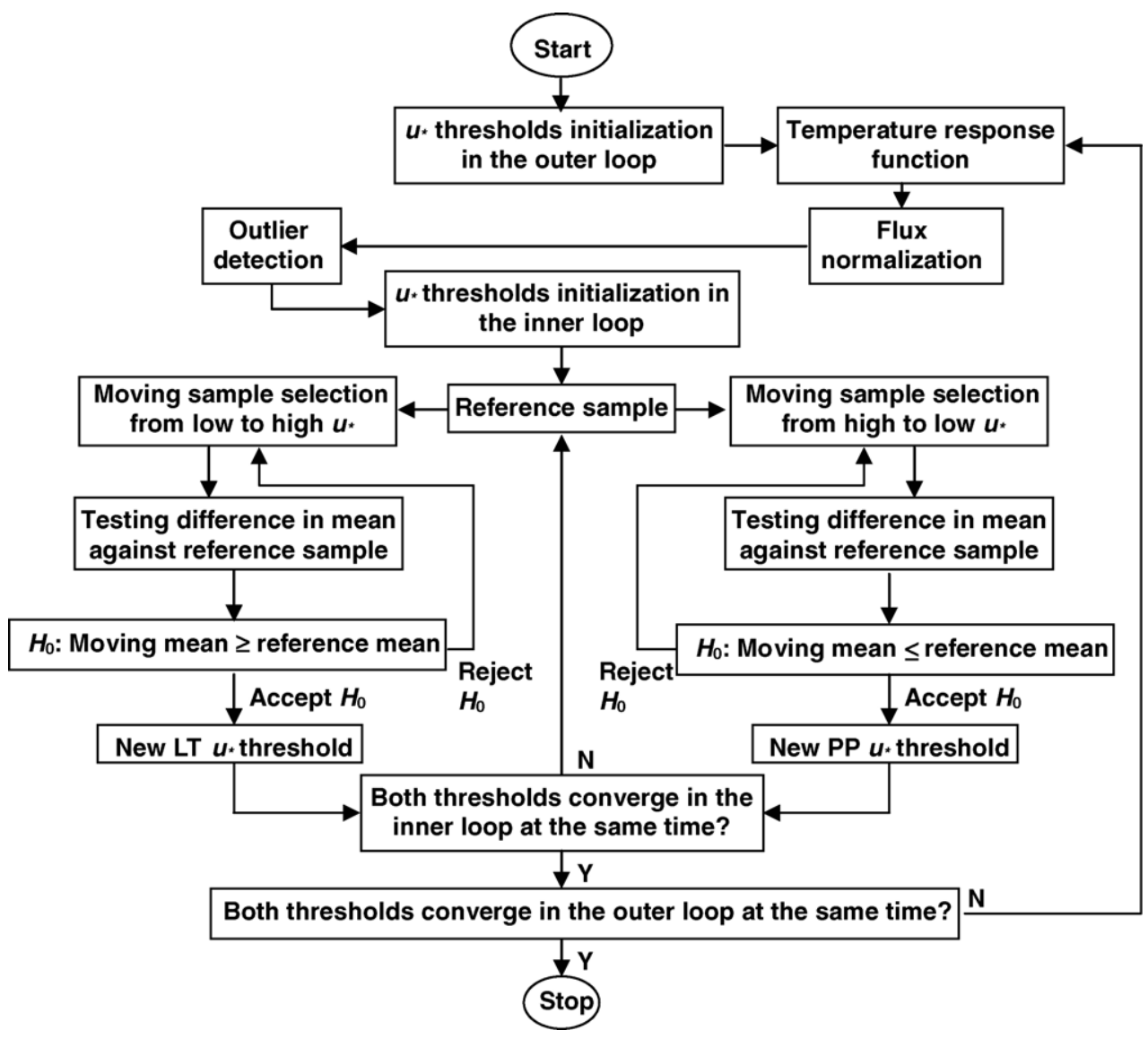

Fig. 4. Flow chart of the moving point test (MPT) method. LT stands for 'low turbulence' and PP stands for 'pressure pumping'. 
the temperature response function and the reference sample.

The specific steps in MPT are as follows (Fig. 4, more explanations follow):

(1) Initialize the $u_{*}$ thresholds for the outer loop by setting $u_{* \mathrm{~L}}=0$ and $u_{*_{\mathrm{H}}}=9999$ (i.e. no filtering).

(2) Develop a temperature response function for ecosystem respiration through regression using data with $u_{*}$ values between $u_{* \mathrm{~L}}$ and $u_{* \mathrm{H}}$ (but excluding data from nights with median $u_{*}$ values less than $u_{* L}$. For the first outer loop iteration, a predefined temperature response function can be used). From this step, the outer loop starts.

(3) Normalize the flux measurements using the temperature response function (i.e. divide the measured flux by the value calculated from the temperature response function). The resultant data are called normalized nighttime fluxes, which form the working dataset.

(4) Conduct an outlier detection test $( \pm 3 \sigma)$ and remove the outliers from the working dataset.

(5) Rank the normalized fluxes in the remaining working dataset from low to high $u_{*}$.

(6) Initialize the $u_{*}$ thresholds for the inner loop by setting $u_{* \mathrm{~L}}=0$ and $u_{*_{\mathrm{H}}}=9999$ (i.e. no filtering). This initialization is done independent of the initialization for the outer loop (Step 1).

(7) Exclude data from nights with median $u_{*}$ less than $u_{*}$.

(8) Use the remaining data with $u_{*}$ between $u_{* \mathrm{~L}}$ and $u *_{\mathrm{H}}$ as the reference sample. From this step, the inner loop starts.

(9) Start from the point with the lowest $u_{*}$ value among the remaining data and take $n$ points
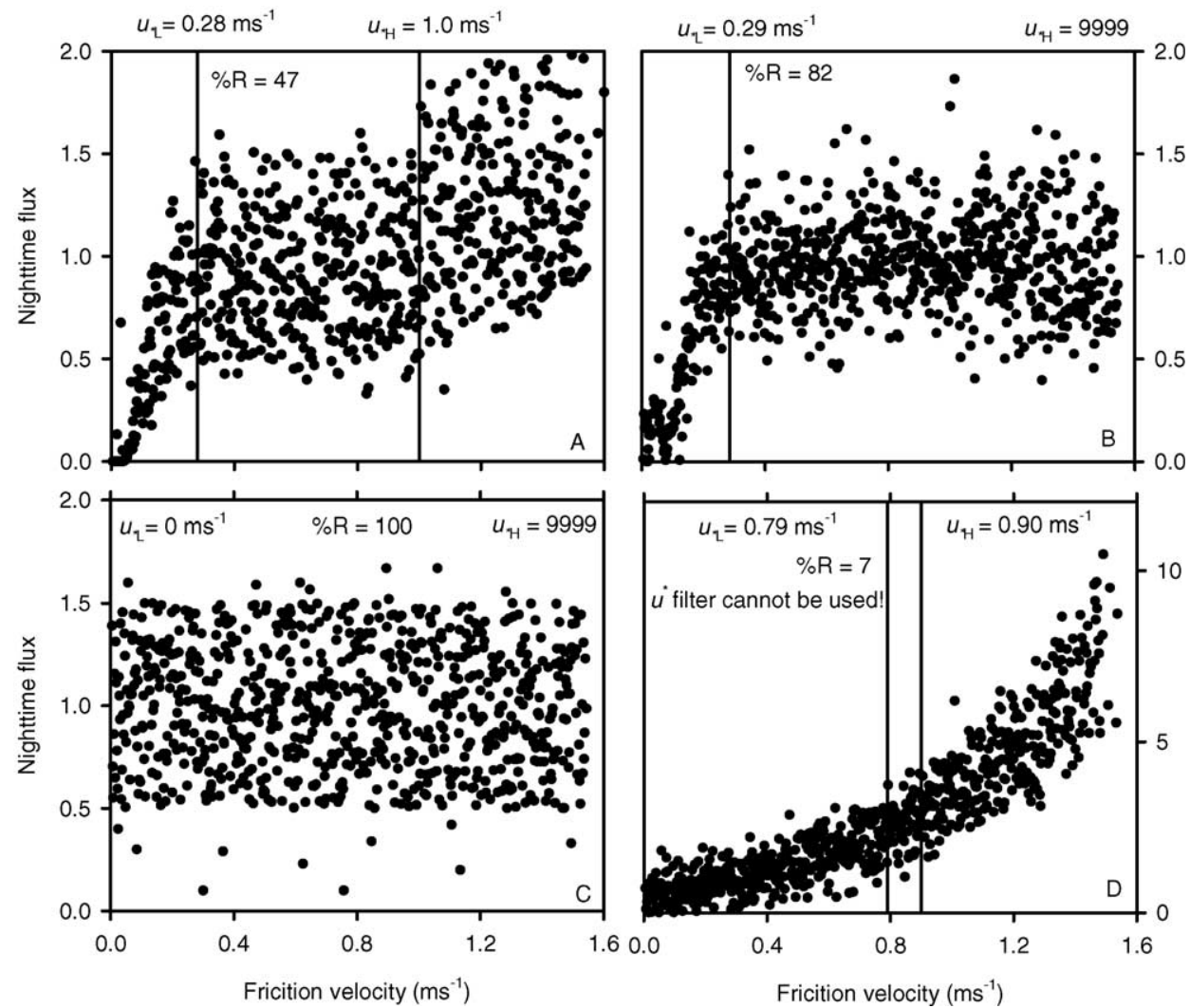

Fig. 5. Four different scenarios used to test the MPT. Note that because the data are artificial, no units are given for the friction velocity and flux. $\% R$ represents the percentage of data left after the screening process, i.e. the data between $u_{*} \mathrm{~L}$ (threshold for low turbulence) and $u * \mathrm{H}$ (threshold for pressure pumping). 
(details follow) with consecutive $u_{*}$ values. This group of points is called the moving sample.

(10) Compare the mean normalized flux of the moving sample $\left(F_{\mathrm{m}}\right)$ to the mean normalized flux of the reference sample $\left(F_{\mathrm{r}}\right)$ using a statistical $t$-test with the null hypothesis $H_{0}$ : $F_{\mathrm{m}} \geq F_{\mathrm{r}}$

(11) If $H_{0}$ is rejected, go back to Step 9 and repeat the steps using the datum point next to the previous starting point as the new starting point (its $u_{*}$ is the next lowest).

(12) If $H_{0}$ cannot be rejected, take the median $u_{*}$ of the moving sample as the new $u_{*}$ threshold $\left(u_{* \mathrm{~L}}\right)$ for measurements that are potentially affected by low turbulence conditions. If $H_{0}$ cannot be rejected at the very first test, no low turbulence effect is assumed $\left(u_{* \mathrm{~L}}=0\right)$.

(13) The determination of the new $u_{* \mathrm{H}}$ parallels the determination of the new $u_{*}$, but the moving sample starts from the highest $u *$ value and $H_{0}$ is
$F_{\mathrm{m}} \leq F_{\mathrm{r}}$. If $H_{0}$ cannot be rejected at the very first test, no pressure pumping effect is assumed $\left(u *_{\mathrm{H}}=9999\right)$.

(14) Compare the new $u_{*_{\mathrm{L}}}$ and $u_{*_{\mathrm{H}}}$ with their values from the previous iteration in the inner loop. If no threshold or only one threshold converges, go back to Step 7 and use the new $u_{*_{\mathrm{L}}}$ and $u_{*_{\mathrm{H}}}$ values for the next round of inner loop iteration.

(15) If both thresholds converge in the inner loop, check to see if both thresholds also converge in the outer loop. If so, the two thresholds are found. If not, go back to Step 2 and use the new thresholds for the next round of outer loop iteration.

The MPT employs two statistical criteria. First, the commonly applied $3 \sigma$ rule is used to detect outliers (points that deviate from the mean by more than three standard deviations). The purpose of outlier detection is to avoid distortion in the determination of low tu-

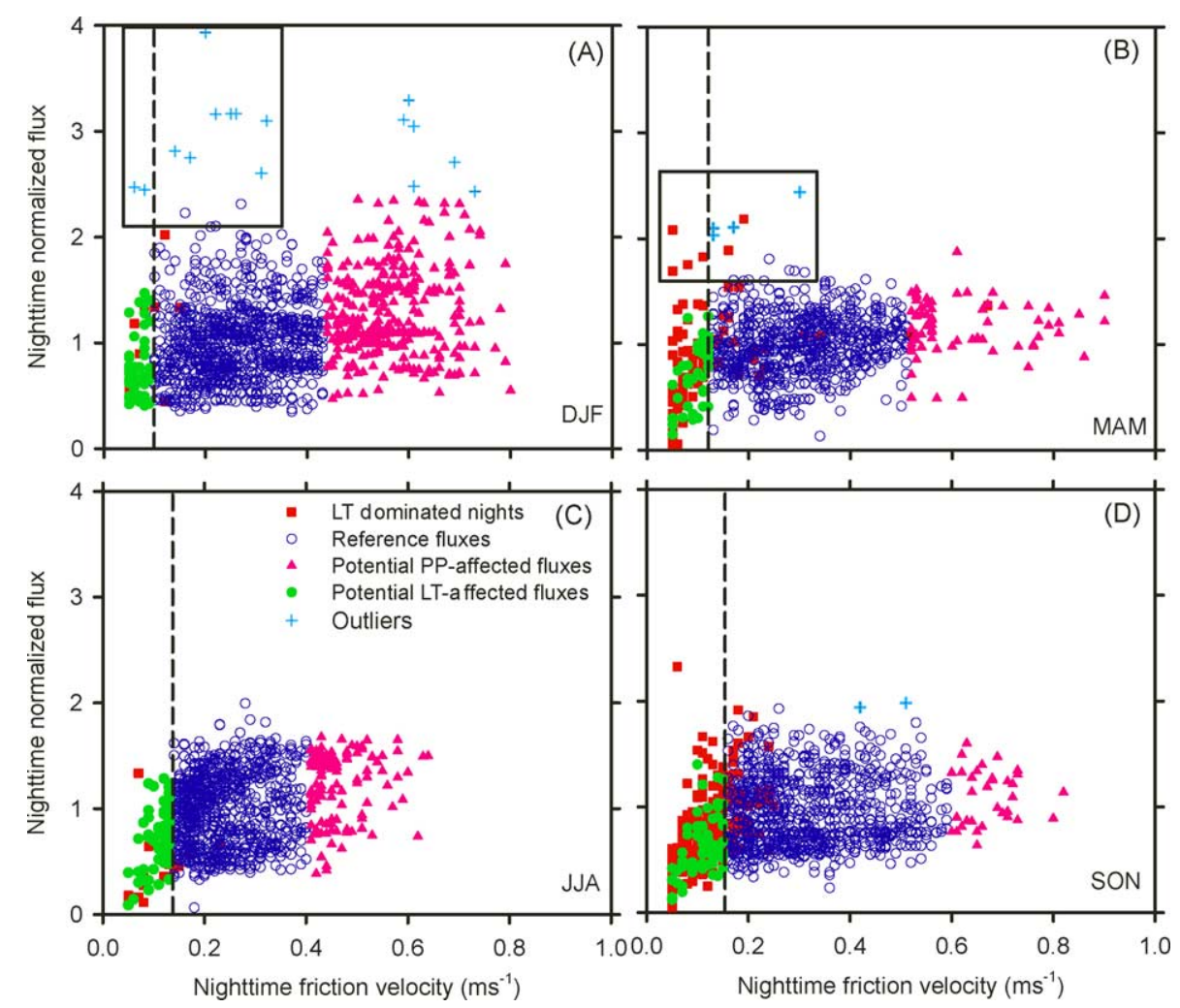

Fig. 6. Demonstration of the application of MPT for the tallgrass prairie site. The vertical dashed lines denote the low turbulence $u *$ thresholds calculated by MPT. Boxes mark unusually large fluxes near the lower end of the observed $u *$ range. 
rbulence and pressure pumping $u_{*}$ thresholds by unusually large fluxes that are occasionally present in nighttime flux measurements. Second, the confidence level in the $t$-test is set conservatively at $\alpha=0.1$ $(\alpha=0.05$ would characterize less data as potentially affected by turbulence regimes). In general, the size of the moving sample $(n)$ is not critical except that it must be large enough to produce meaningful statistics and small enough to avoid including any pattern (between the normalized flux and $u_{*}$ ) in the moving window. Obviously, the total number of data points in the test $(N)$ should be much larger than $n$. Otherwise the choice of $n$ can affect the estimated $u_{*}$ thresholds. We recommend that $N>15 n$. In this paper, $n=25$. Although the size of the moving sample is pre-selected and fixed during the iterations, the size of the reference sample is dynamic. In fact, it always shrinks after each iteration in the inner loop. In addition, the $t$-test requires one to make a choice between two assumptions regarding the variances of the two samples to be compared: equal variances versus unequal variances. In the cases tested in this study, we found that overall the two assumptions produce consistent estimates of $u_{*} \mathrm{~L}$ and $u_{*_{\mathrm{H}}}$. However, when sample sizes are small or noises are large, the two assumptions may lead to different estimates. In flux $-u_{*}$ scatter plots, we often see that variations tend to be smaller at low $u_{*}$. Therefore it seems the unequal variance assumption should be used. We adopt the unequal variance assumption in this paper.

Table 1

Summary statistics generated from the MPT for the seven sites tested in this study

\begin{tabular}{|c|c|c|c|c|}
\hline & & $u_{* \mathrm{~L}}$ & $u_{* \mathrm{H}}$ & $\% R$ \\
\hline \multirow[t]{4}{*}{ Tallgrass prairie (1999) } & DJF & 0.1 & 0.43 & 70 \\
\hline & MAM & 0.13 & 0.51 & 77 \\
\hline & JJA & 0.14 & 0.4 & 80 \\
\hline & SON & 0.16 & 0.59 & 70 \\
\hline \multirow[t]{4}{*}{ Harvard Forest (1992-2001, 2003) } & DJF & $0.29( \pm 0.12)$ & $0.86( \pm 0.08)$ & $53( \pm 15)$ \\
\hline & MAM & $0.25( \pm 0.06)$ & $0.74( \pm 0.08)$ & $52( \pm 9)$ \\
\hline & JJA & $0.08( \pm 0.03)$ & $0.53( \pm 0.09)$ & $78( \pm 5)$ \\
\hline & SON & $0.13( \pm 0.02)$ & $0.72( \pm 0.07)$ & $72( \pm 6)$ \\
\hline \multirow[t]{4}{*}{ Scots pine forest (1997) } & DJF & 0.00 & 1.10 & 98 \\
\hline & MAM & 0.25 & 9999 & 60 \\
\hline & JJA & 0.12 & 0.25 & 34 \\
\hline & SON & 0.18 & 9999 & 79 \\
\hline \multirow[t]{3}{*}{ Aspen forest (1994) } & $\mathrm{JF}$ & 0.10 & 9999 & 85 \\
\hline & MAM & 0.04 & 1.09 & 95 \\
\hline & JJA & 0.02 & 0.46 & 82 \\
\hline \multirow[t]{3}{*}{ Aspen forest (no storage, 1994) } & $\mathrm{JF}$ & 0.20 & 9999 & 73 \\
\hline & MAM & 0.37 & 9999 & 37 \\
\hline & JJA & 0.24 & 0.72 & 35 \\
\hline \multirow[t]{4}{*}{ Oak-grass Savanna (2003) } & DJF & 0.11 & 0.27 & 48 \\
\hline & MAM & 0.07 & 0.23 & 57 \\
\hline & JJA & 0.11 & 0.21 & 35 \\
\hline & SON & 0.08 & 0.33 & 73 \\
\hline \multirow[t]{4}{*}{ Annual grassland (2003) } & DJF & 0.00 & 0.14 & 77 \\
\hline & MAM & 0.01 & 0.09 & 52 \\
\hline & JJA & 0.00 & 0.18 & 96 \\
\hline & SON & 0.02 & 0.27 & 95 \\
\hline \multirow[t]{4}{*}{ Amazonian forest (2002) } & DJF & 0.15 & 0.54 & 72 \\
\hline & MAM & 0.17 & 9999 & 53 \\
\hline & JJA & 0.16 & 0.23 & 24 \\
\hline & SON & 0.16 & 0.36 & 56 \\
\hline
\end{tabular}

$u_{* \mathrm{~L}}$ and $u_{* \mathrm{H}}$ are friction velocity thresholds for low turbulence and pressure pumping effects, respectively $\left(\mathrm{ms}^{-1}\right)$. \% $R$ denotes the percentage of data left after the screening process, i.e. the data between $u_{* \mathrm{~L}}$ and $u *_{\mathrm{H}}$. Canopy storage is included unless stated otherwise. For the Harvard Forest site, values given are the means for the seasons and years indicated and values in parenthesis are $90 \%$ confidence intervals. 
The temperature response function is described as (Gu et al., 2002):

$R_{\mathrm{e}}=c_{1} \mathrm{e}^{c_{2}\left[c_{3} T_{\mathrm{a}}+\left(1-c_{3}\right) T_{\mathrm{s}}\right]}+d_{1} \mathrm{e}^{d_{2} T_{\mathrm{s}}}$

where $c_{1}, c_{2}, c_{3}, d_{1}$ and $d_{2}$ are the regression coefficients, $T_{\mathrm{s}}$ the soil temperature (at $\sim 5 \mathrm{~cm}$ depth), and $T_{\mathrm{a}}$ the air temperature (above the canopy). Eq. (1) amounts to a respiration model of two carbon pools. The first term on the right hand side is expected to capture the above-ground biomass respiration while the second term represents soil respiration. Instead of using only air temperature in the first term on the right hand side of (1), we employ $c_{3} T_{\mathrm{a}}+\left(1-c_{3}\right) T_{\mathrm{s}}$ to reflect the effects of vertical temperature gradients on above-ground biomass respiration. $c_{3}$, a weighting coefficient, changes within the interval of $(0,1)$.

During the iterations of the inner loop, the median $u_{*}$ of the moving sample is taken as the new threshold when the alternative hypothesis is favored. Convergence is reached when the same median $u *$ is found for two successive iterations. The iterations are conducted in juxtaposition for the low turbulence test and the pressure pumping effect test. The inner loop terminates only when both tests converge simultaneously. This is necessary because the reference sample is shared by both tests. The new thresholds are then used by the outer loop to determine a new temperature response function. Fluxes are normalized again using the new temperature response function and then fed into the inner loop. The final $u_{*}$ thresholds are determined when both the inner and outer loops converge to the same values. The reference sample in the last inner loop iteration is then considered as consisting of biological fluxes only. Normally, convergence is reached very quickly in terms of the number of inner and outer loop iterations. Occasionally, the new threshold may alternate between two consecutive $u_{*}$ values and the MPT enters into a repeating cycle. This can happen because the $u *$ values in the measurement set are discrete. To overcome this,

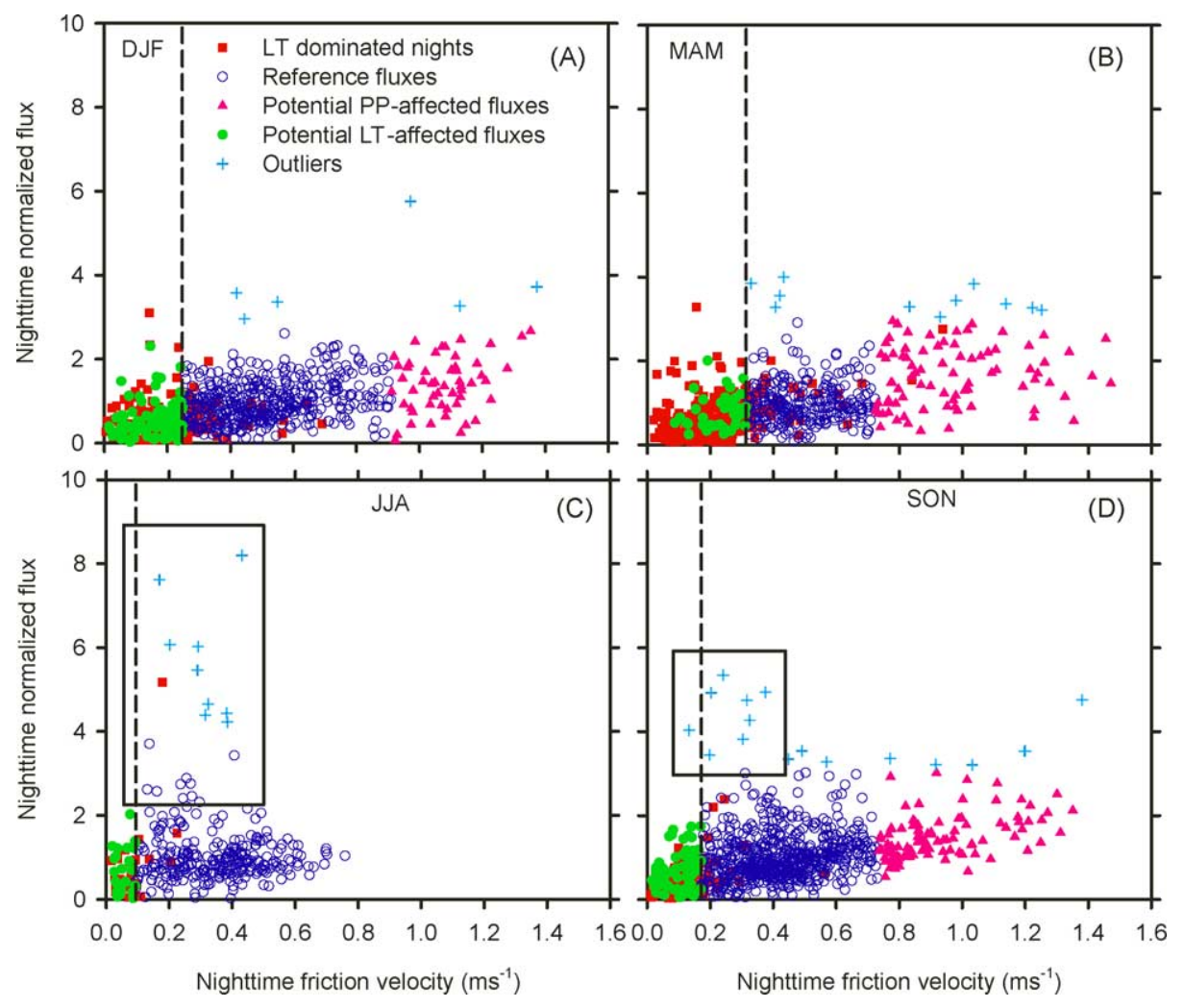

Fig. 7. Same as the previous figure but for the Harvard Forest site. 
the MPT retains the thresholds from the previous iterations. If a repeating cycle occurs, the first point at which the MPT enters into the cycle is taken as the new threshold.

A salient feature of the MPT is that the automated procedure does not presuppose the existence of $u_{*}$ thresholds. On the one hand, if there is no pattern in the scatter plot between the normalized flux and $u_{*}$, MPT outputs 0 for $u_{*_{\mathrm{L}}}$ and 9999 for $u_{*_{\mathrm{H}}}$. On the other hand, if the normalized flux tends to increase continuously with $u_{*}$ (this would be a case in which $u_{*}$ cannot be used as a criterion for filtering nighttime fluxes), the $u_{*_{\mathrm{L}}}$ and $u_{*_{\mathrm{H}}}$ produced by MPT become very close to each other, leaving only a small fraction of the data in the final reference sample after the filtering process is completed. It is even conceivable that if the normalized flux increases sharply with $u_{*}$, $u_{*_{\mathrm{L}}}$ and $u_{*_{\mathrm{H}}}$ can overlap, thus filtering out all data. Therefore, the closeness between the $u_{* \mathrm{~L}}$ and $u_{* \mathrm{H}}$ values, as well as the percentage of data left after the screening process $(\% R)$, can serve as warning signals for this pattern. In the following section, we will demonstrate these scenarios.

\section{Case demonstrations}

The MPT method was tested to determine whether it could generate $u_{*}$ thresholds consistent with those obtained from visual examination. We first used artificial datasets representing different scenarios in the relationship between nighttime NEE versus $u_{*}$ (Fig. 5). The artificial datasets were designed so that the transition in the relationship between the normalized fluxes and $u_{*}$ could be visually recognized easily in the scatter plots. They covered four scenarios and were used to test the inner loop (the outer loop is for flux normalization, which is not necessary for an artificial dataset). The first scenario (Fig. 5A) is a reflection of our conceptual model about the general relationship between observed nighttime fluxes and $u_{*}$, which was introduced in the beginning of the

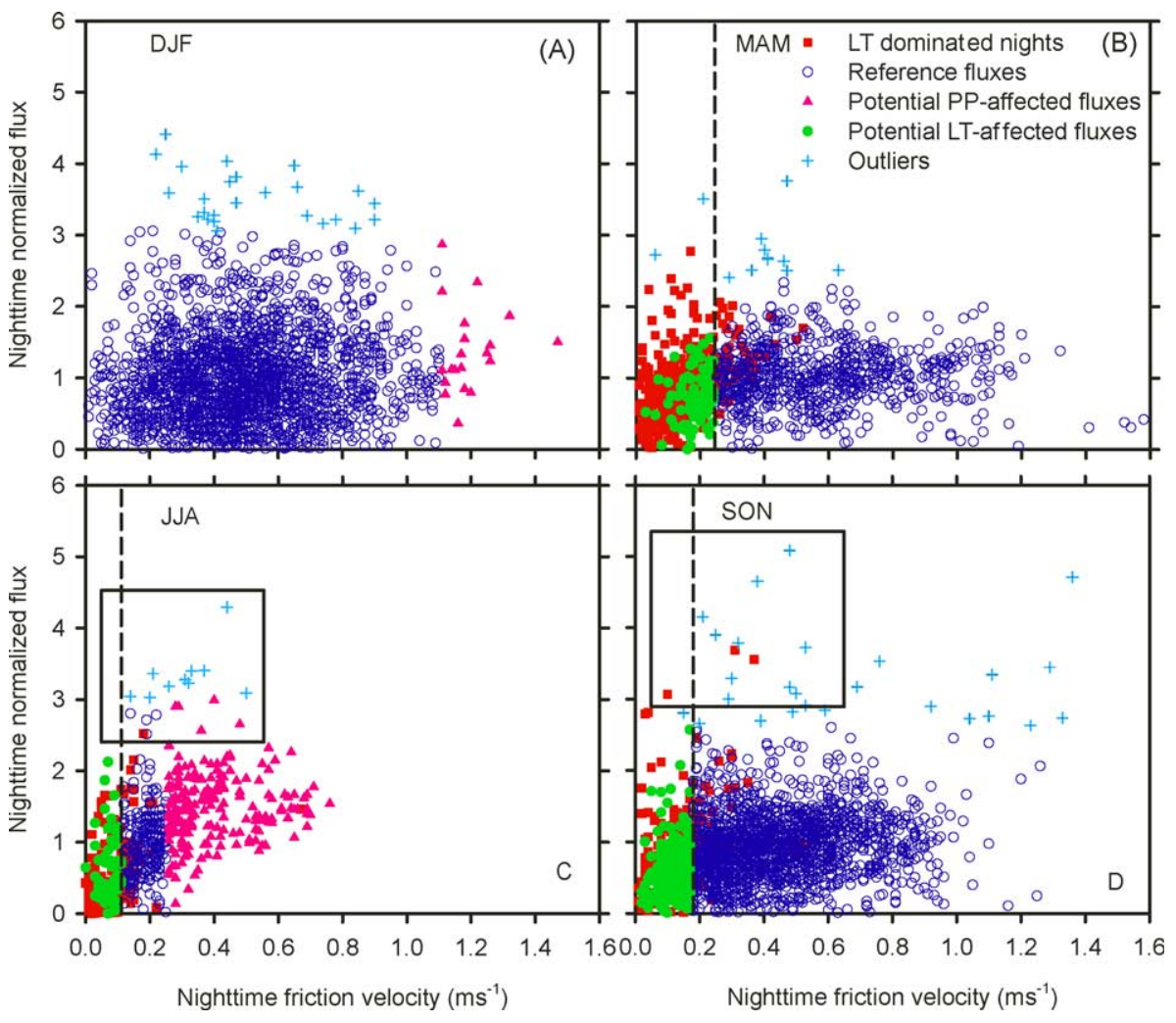

Fig. 8. Same as the previous figure but for the Scots pine forest site. 
previous section. Other scenarios (Fig. 5C and D) represent specific extensions of our conceptual model.

In the first two scenarios, MPT placed the $u_{*}$ thresholds at the expected locations. In the third scenario, MPT correctly output 0 for $u_{* \mathrm{~L}}$ and 9999 for $u_{* \mathrm{H}}$, indicating no pattern exists in the dataset, in agreement with the visual examination. In the fourth scenario, MPT still output values for $u_{* \mathrm{~L}}$ and $u_{* \mathrm{H}}$.
However, it placed the $u_{*_{\mathrm{L}}}$ and $u_{*_{\mathrm{H}}}$ thresholds very close to each other, and accepted only a small fraction of the data as "biological fluxes" (7\%). The low percentage of data left indicates that it is not appropriate to use $u_{*}$ as a criterion for this artificially constructed scenario.

We then used actual measurements to test both the inner and outer loops in the MPT method. The data

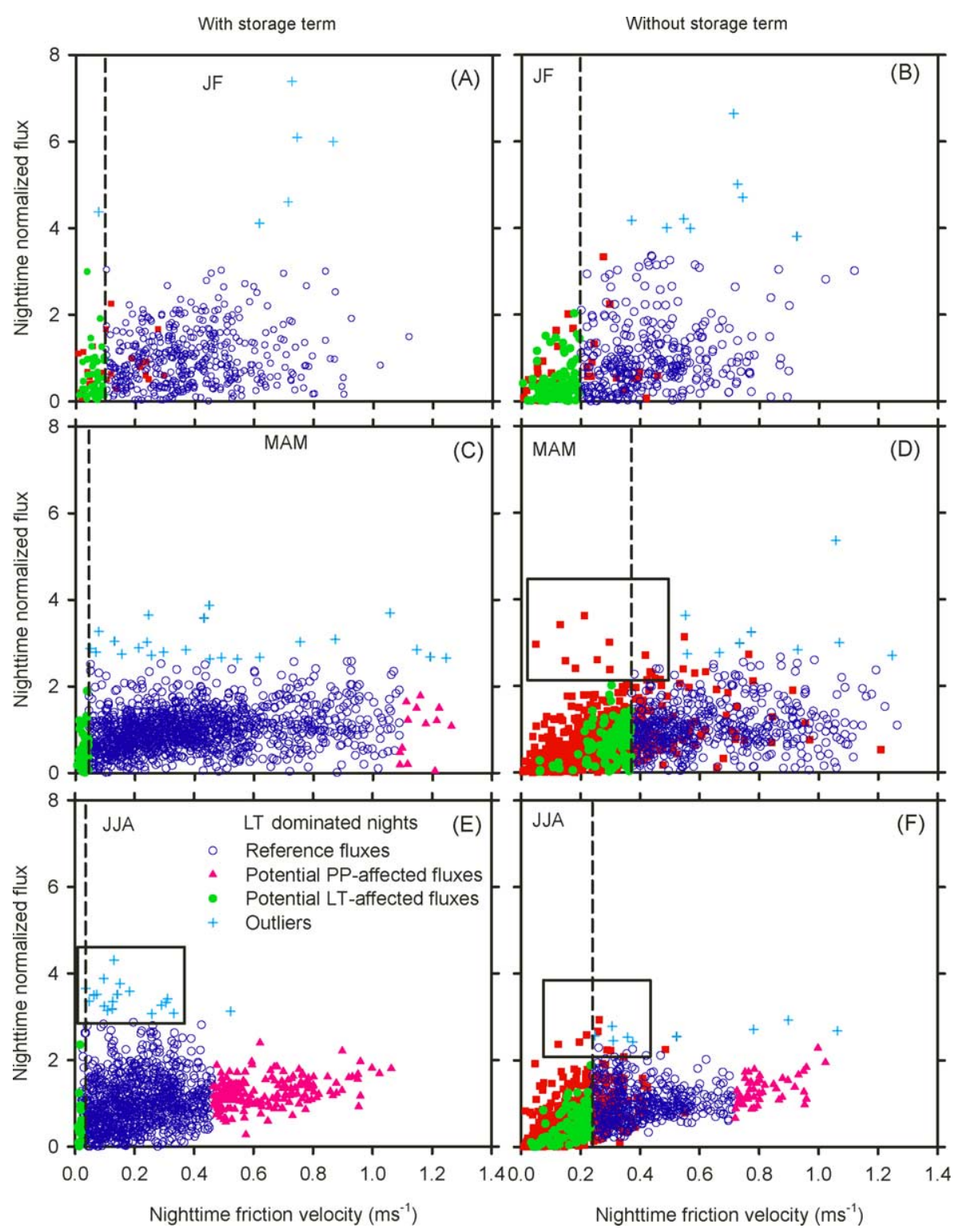

Fig. 9. Same as the previous figure but for the aspen forest site. Results of applying MPT to fluxes without canopy storage corrections are also shown. 


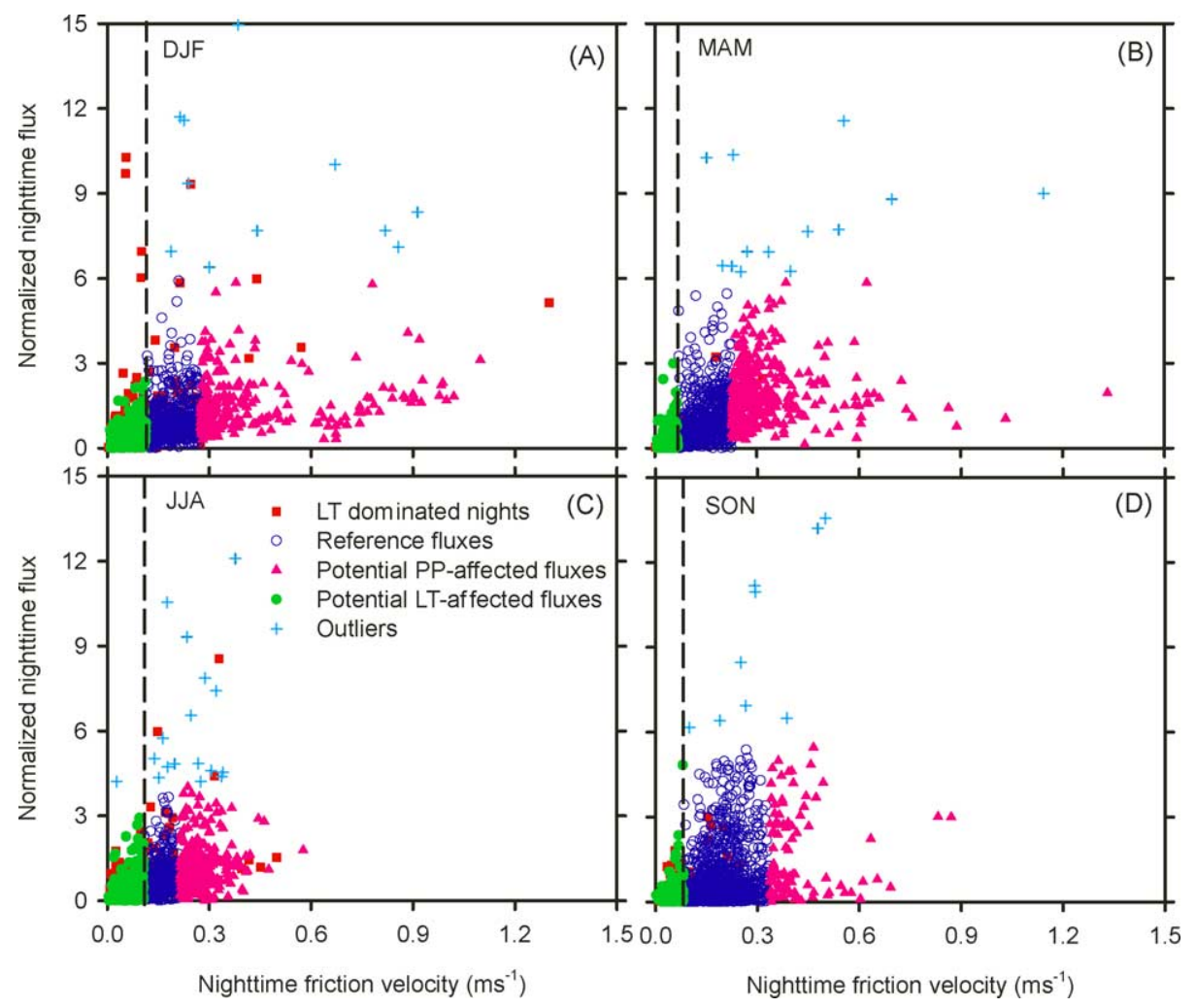

Fig. 10. Same as the previous figure but for the oak-grass Savanna site.

were from seven sites covering a wide variety of vegetation types. Four sites were already mentioned in Section 2. The three additional sites were an oakgrass Savanna (Xu and Baldocchi, 2003) and annual grassland (Xu and Baldocchi, 2003) under Mediterranean climate in northern California and an oldgrowth Amazonian forest in Brazil (Saleska et al., 2003). The data were from 1999 for the tallgrass prairie site, 1997 for the Scots pine forest site, 1994 for the aspen forest site, 2003 for the two Californian sites, and 2002 for the Amazonian forest. For the Harvard Forest site, we used data from multiple years (1992-2001 and 2003). The soil temperature measurements were not available for 2002, which was excluded from the analysis. The data were grouped into seasons and $u *_{\mathrm{H}}$ and $u *_{\mathrm{L}}$ were identified for each season and for the Harvard Forest site, each year too. For the aspen site, we did not have sufficient data from September to December so these months were not included. The grouping was for demonstration purposes only. One may instead choose to use moving windows that cover a period of less than 3 months. The results are displayed in Figs. 6-12. Summary statistics from these tests are given in Table 1. For the Harvard Forest site, the scatter plots for 1 year (2001, Fig. 7) and means of all years (Table 1 and Fig. 12) are presented. In order to examine how the canopy storage term affects the determination of $u *$ thresholds, we also conducted a run for a case in which the canopy storage term was intentionally removed from the flux at the aspen site (Fig. 9, Table 1).

Overall, the $u *$ thresholds identified by MPT agreed with visual expectations. The influence of low turbulence was detected by MPT for almost all seasons at all sites. MPT also found larger normalized fluxes, which were statistically significant and which we assume to be affected by pressure pumping effects, near the high end of the observed $u *$ range for most seasons and sites (pink triangles in Figs. 6-12). This pattern can be visually seen, for example, in Fig. 6A (winter at the tallgrass prairie site), Fig. 7D (fall at the 


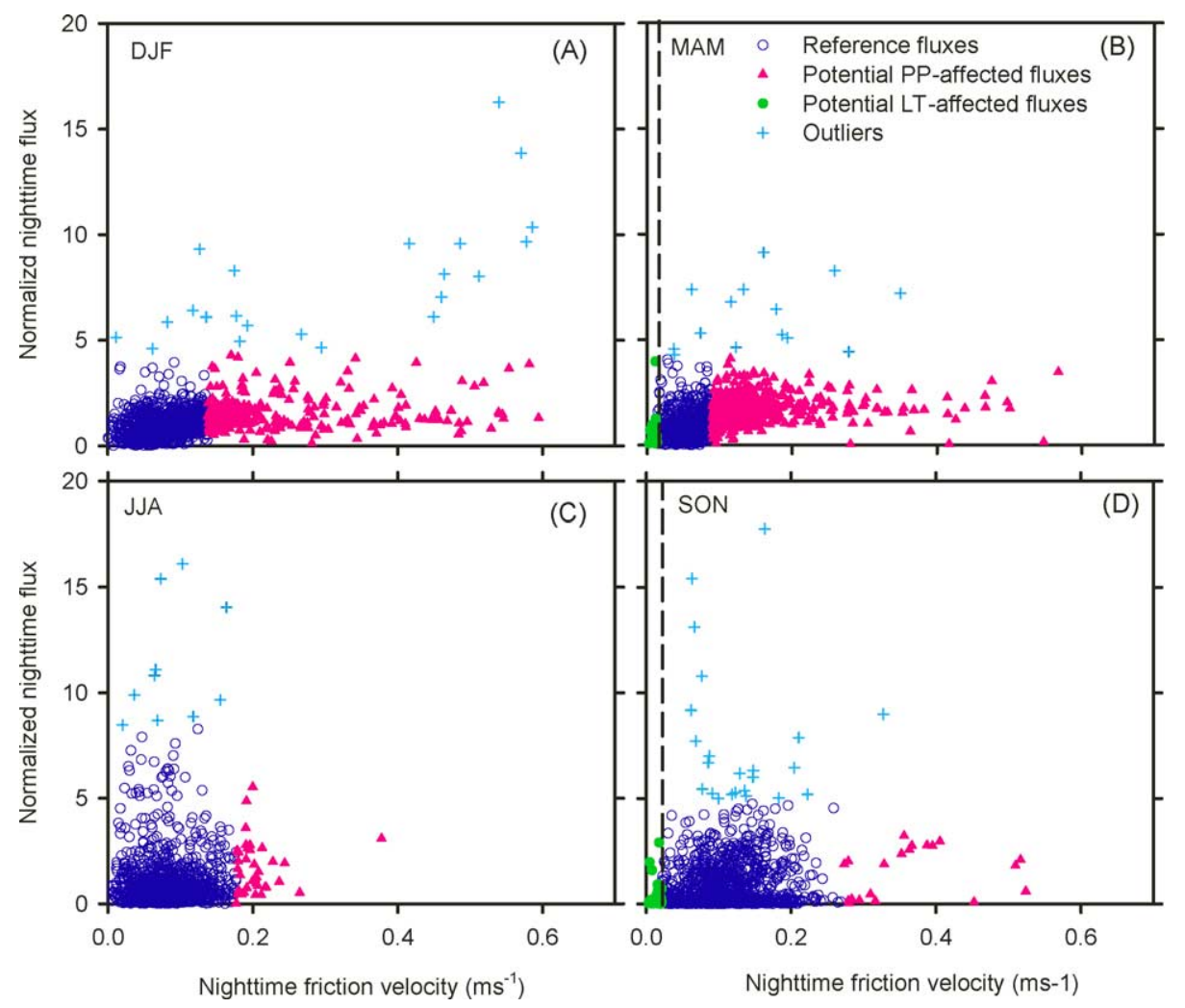

Fig. 11. Same as the previous figure but for the annual grassland site.

Harvard Forest site), and Fig. 9E (summer at the aspen forest site). Identifying and filtering out nights dominated by low turbulence conditions as part of the nighttime flux treatment appear to be warranted since during these nights measurements often show great variability with no clear patterns (for example, Figs. 6B, D, 7B, and 8B, red squares).

While previous studies have applied a single $u_{*}$ threshold to screen yearlong measurements, we found that both $u_{*_{\mathrm{H}}}$ and $u_{*_{\mathrm{L}}}$ vary considerably with season (Table 1). For the Harvard Forest site, the mean $u_{*} \mathrm{~L}$ changes from 0.29 in winter to $0.08 \mathrm{~ms}^{-1}$ in summer and the mean $u_{* \mathrm{H}}$ changes from 0.86 in winter and $0.53 \mathrm{~ms}^{-1}$ in summer. Both $u_{*_{\mathrm{H}}}$ and $u_{*_{\mathrm{L}}}$ are highest in winter and lowest in summer. Although we warn that we should not determine the $u_{*}$ threshold using the yearly time window, it is interesting to note that the mean $u_{*_{\mathrm{L}}}$ for all seasons and years at the Harvard Forest site is $0.19 \pm 0.02 \mathrm{~ms}^{-1}$. For comparison, Barford et al. (2001) used $0.20 \mathrm{~ms}^{-1}$ as a cutoff $u *$ threshold at the same site. For other sites, we were not able to conduct a rigorous seasonal variation analysis because only one year's data were used.

Neglecting canopy storage significantly increases $u * \mathrm{~L}$ and reduces the amount of measurements identified as biological fluxes (i.e. fluxes in the final reference sample) for all three seasons studied at the aspen site (Fig. 9, compare plots B, D, and F with A, C, and $\mathrm{E}$, respectively; also see Table 1).

In general, more data were identified as biological fluxes than as measurements influenced by turbulence regimes or as outliers at all sites (Table 1, Figs. 6-12). The notable exceptions were the summers at the Scots pine forest site (Fig. 8C), the oak Savanna site (Fig. 10C), and the Amazonian forest site (Fig. 12C) for which only 34,35 , and $24 \%$ of the measurements were identified as biological fluxes, respectively (Table 1). The other exceptions were the spring and summer seasons at the aspen forest site when canopy storage was ignored. For the spring, $37 \%$ of the 

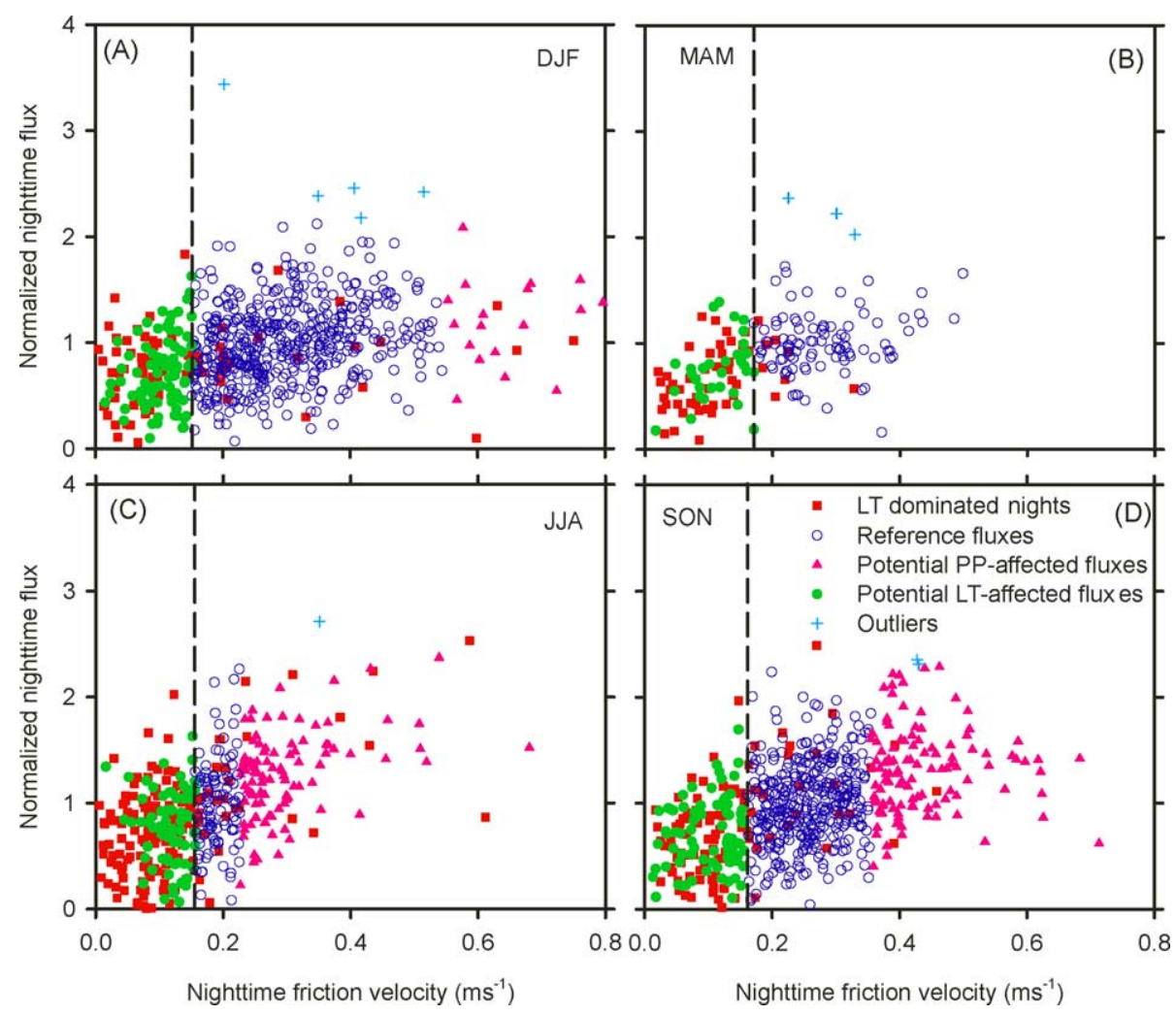

Fig. 12. Same as the previous figure but for the Amazonian forest site.

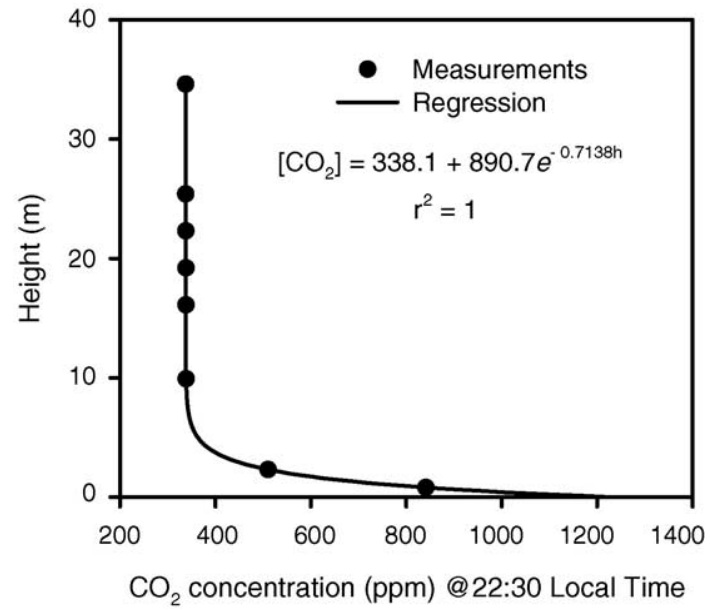

Fig. 13. A measured $\mathrm{CO}_{2}$ concentration profile from the aspen forest site to illustrate how big the $\mathrm{CO}_{2}$ concentration gradient near the ground surface can be during nighttime. measurements were identified as biological fluxes. For the summer, $35 \%$ of the measurements were identified as biological fluxes.

\section{Unusually large fluxes at low $u_{*}$ and continuous increase of fluxes with $\mathbf{u}$ *}

We notice that there is often a 'hump' in the scatter plot of the normalized fluxes versus $u_{*}$ at values of $u_{*}$ that are near the lower end of the observed $u_{*}$ range (see plots in Figs. 6-12, some are marked with boxes). This phenomenon apparently is not site-related since it occurs at all sites included in this study. The majority of these points are already characterized as outliers and therefore do not affect the determination of $u_{*_{\mathrm{L}}}$. Similar patterns can also be observed in scatter plots of NEE (not normalized) against $u *$ (data not shown). Xu 
and Baldocchi (2004) reported that soil efflux often increased after rainfall events possibly due to displacement of air in soil pores by water and reactivation of microbial activities. This might account for some of the unusually large fluxes. However, it is unlikely the only explanation since most of these points are sporadic and often follow a very calm period with small observed fluxes. We suspect that the inadequacy of the profiling systems might contribute to these high values. Inside vegetation canopies, calm conditions during nighttime can lead to buildup of $\mathrm{CO}_{2}$ concentration very close to the ground surface $\left(\mathrm{CO}_{2}\right.$ molecule is heavier than the mean air). A model prediction by $\mathrm{Gu}$ et al. (1999) showed that nighttime $\mathrm{CO}_{2}$ concentration inside plant canopies can increase exponentially towards the soil surface under stable conditions, leading to a sharp gradient within the first couple meters above the ground. Fig. 13 shows a measured $\mathrm{CO}_{2}$ concentration profile and an almost perfect exponential fit for a summer night at the aspen site in 1994. We estimated that if increased turbulence removes this profile within a period of $30 \mathrm{~min}$, the storage change would amount to nearly $30 \mu \mathrm{mol} \mathrm{m} \mathrm{s}^{-2} \mathrm{~s}^{-1}$ and about $80 \%$ of this flux is caused by change in the first couple meters. Clearly, it is critical to measure change in canopy storage accurately, particularly within the first couple meters above the ground surface. However, the profiling systems at most forest flux tower sites only have one or two levels of $\mathrm{CO}_{2}$ concentration measurements within the first few meters above the ground and are not capable of capturing sharp concentration gradients near the forest floor. These profiling systems may not work adequately for the determination of nighttime $\mathrm{CO}_{2}$ flux above the canopy.

Another pattern we notice is that in some cases, nighttime fluxes appear to continue to increase over the whole range of observed $u *$ (for example, Figs. 8C and 12). This leads to a very short range between $u_{*} \mathrm{~L}$ and $u_{*_{\mathrm{H}}}$. Continuous increase of nighttime fluxes with $u *$ has been noted in previous studies (Massman and Lee, 2002). We suspect that this might again be related to inadequate profiling. It is expected that overall the storage term should decrease as $u_{*}$ increases (Massman and Lee, 2002). If the profiling system is not adequate, then this decreasing trend may not be captured, leading to continuous increase of nighttime fluxes with $u_{*}$. In order to avoid this problem, a single profile may not be enough. Storage change is fundamentally a volume-based variable. During a calm night, vertical turbulent exchanges can be localized, leading to strong horizontal heterogeneities in $\mathrm{CO}_{2}$ concentration even at perfectly flat sites. Multiple profiles at different locations with the flux footprint may be needed in order to estimate the flux storage changes accurately.

\section{Conclusions and recommendations}

Underestimation of nighttime fluxes by the eddy covariance technique is perhaps one of the largest sources of uncertainty in the estimation of long-term net ecosystem productions through direct flux observations. Careful, consistent treatment of nighttime fluxes is needed to minimize this uncertainty. As an attempt in this direction, we have developed an automated, objective approach (moving point test or MPT) to determine appropriate thresholds for the $u_{*}$ filter. While MPT is a practical method, subject to replacement when a sound, theoretically based approach is available, it is testable and reproducible and can be applied uniformly over time and across different sites. It has considerable advantages over the subjective, visual examination approach. Tests showed that MPT can handle a variety of possible relationships between observed nighttime fluxes and $u_{*}$. MPT identifies thresholds that are consistent with thresholds determined by visual judgment. The method determines $u_{*}$ thresholds when they exist and also identifies instances where no nighttime flux correction is needed or it is not appropriate to use $u_{*}$ as a criterion for correction.

We point out that the general framework developed in this paper is not limited solely to the application of the $u_{*}$ filter. Some researchers prefer to use criteria other than $u$ * for low turbulence conditions, including the mean wind speed (e.g. Suyker and Verma, 2001) and the buoyancy forcing fraction (Staebler and Fitzjarrald, 2004). Should these criteria be proven superior to the $u *$ filter, the procedures and approach of the MPT are still applicable and could be modified accordingly.

While overcoming the nighttime flux problem probably requires new theoretical and technological developments, there are two steps we can take 
currently to minimize its effect based on findings from this study. One is to avoid nighttime measurement gaps as much as possible so that more data can be used in the screening process. This is particularly important for summer nights because of the short-time duration and frequent calm conditions, which greatly limit the number of usable data (Table 1). The second is to improve estimation of canopy storage changes. We found that inadequate $\mathrm{CO}_{2}$ profiling may be responsible for some of the irregular patterns commonly observed in scatter plots of nighttime NEE versus $u_{*}$ across different eddy covariance flux sites. Here we emphasize the need for better determination of canopy storage changes by monitoring $\mathrm{CO}_{2}$ concentration at more levels near the soil surface than currently used by the flux community. There is also a need for multiple profiles at different locations of the flux footprint so that a volume-averaged estimate of storage change can be made. Accurate measurement of canopy storage changes will improve the reliability of the $u_{*}$ filter by helping avoid the problem of double counting and by retaining more valid measurements after the filtering process (because smaller $u_{*}$ thresholds for low turbulence influences would be needed with an adequate profiling system).

We found that in general fluxes at the higher end of the $u *$ range are statistically significantly higher than fluxes with intermediate or low $u_{*}$ values. The pervasiveness of this phenomenon is a little surprising to us. It may indicate that pressure pumping effects may be stronger than we thought or there may be other unknown factors that exist at high friction velocity to influence turbulent flux measurements. More studies are needed to understand micrometeorological or physical processes responsible for this phenomenon.

At this stage, it is debatable whether to include the data points identified by MPT as measurements potentially affected by pressure pumping effects in the annual carbon budget calculation or whether to replace them with calculated values. Although they are real fluxes (unlike fluxes affected by low turbulence conditions, which underestimate the real fluxes) and it seems logical to include them in the annual carbon budget calculation, they are larger presumably because of additional contributions from air pores inside snows or soils. The profiling systems do not account for storage changes in snow or soil pores. $\mathrm{CO}_{2}$ depleted from these pores under pressure fluctuations may be replenished later under calmer conditions, which is not detected by the profiling systems. We therefore suggest that they are replaced with calculated values, together with data obtained under low turbulence conditions.

We must point out that the MPT method is not meant to be a final solution to the nighttime flux issue. Continuous theoretical and experimental researches are still needed to overcome the challenges in measuring nighttime fluxes accurately.

\section{Acknowledgements}

This paper is a contribution to the AmeriFlux and Fluxnet projects at ORNL. The AmeriFlux data and data synthesis (data assimilation) activities at ORNL are sponsored by the U.S. Department of Energy, Office of Science, Biological and Environmental Research Program, Environmental Science Division. NASA's Office of Earth Science (U.S. National Aeronautics and Space Administration, Office of Earth Science, Terrestrial Ecology Program, Activity No. 46WM16401) supported the FLUXNET-DIS project. ORNL is managed by UT-Battelle, LLC, for the U.S. Department of Energy under the contract DE-AC05-00OR22725. The MPT code is freely available from the Carbon Dioxide Information Analysis Center (CDIAC), Environmental Sciences Division, Oak Ridge National Laboratory.

\section{References}

Aubinet, M., Grelle, A., Ibrom, A., Rannik, U., Moncrieff, J., Foken, T., Kowalski, A.S., Martin, P.H., Berbigier, P., Bernhofer, C., Clement, R., Elbers, J., Granier, A., Grunwald, T., Morgenstern, K., Pilegaard, K., Rebmann, C., Snijders, W., Valentini, R., Vesala, T., 2000. Estimates of the annual net carbon and water exchange of forests: the EuroFlux methodology. Adv. Ecol. Res. 30, 113-175.

Baldocchi, D.D., Finnigan, J., Wilson, K., Paw, U.K.T., Falge, E., 2000. On measuring net ecosystem carbon exchange over tall vegetation on complex terrain. Boundary-layer Meteorol. 96, 257-291.

Baldocchi, D.D., Falge, E., Gu, L., Olson, R., Hollinger, D., Running, S., Anthoni, P., Bernhofer, C., Davis, K., Fuentes, J., Goldstein, A., Katul, G., Law, B., Lee, X., Malhi, Y., Meyers, T., Munger, J.W., Oechel, W., Pilegaard, K., Schmid, H.P., Valentini, R., Verma, S., Vesala, T., Wilson, K., Wofsy, S.C., 2001. FLUXNET: a new tool to study the temporal and spatial 
variability of ecosystem-scale carbon dioxide, water vapor and energy flux densities. Bull. Am. Meteorol. Soc. 82, 2415-2434.

Barford, C.C., Wofsy, S.C., Goulden, M.L., Munger, J.W., Pyle, E.H., Urbanski, S.P., Hutyra, L., Saleska, S.R., Fitzjarrald, D., Moore, K., 2001. Factors controlling long- and short-term sequestration of atmospheric $\mathrm{CO}_{2}$ in a mid-latitude forest. Science 294, 1688-1691.

Barr, A.G., Griffis, T.J., Black, T.A., Lee, X., Staebler, R.M., Fuentes, J.D., Chen, Z., Morgenstern, K., 2002. Comparing the carbon budgets of boreal and temperate deciduous forest stands. Can. J. Forest Res. 32, 813-822.

Black, T.A., Chen, W.J., Barr, A.G., Arain, M.A., Chen, Z., Nesic, Z., Hogg, E.H., Neumann, H.H., Yang, P.C., 2000. Increased carbon sequestration by a boreal deciduous forest in years with a warm spring. Geophys. Res. Lett. 27, 1271-1274.

Finnigan, J., 1999. A comment on the paper by Lee (1998): on micrometeorological observations of surface-air exchange over tall vegetation. Agric. Forest Meteorol. 97, 55-64.

Goulden, M.L., Munger, J.W., Fan, S.M., Daube, B.C., Wofsy, S.C., 1996. Measurements of carbon sequestration by long-term eddy covariance: methods and a critical evaluation of accuracy. Global Change Biol. 2, 169-182.

Grace, J., Lloyd, J., Mcintyre, J., Miranda, A.C., Meir, P., Miranda, H.S., Nobre, C., Moncrieff, J., Massheder, J., Malhi, Y., Wright, I., Gash, J., 1995. Carbon-dioxide uptake by an undisturbed tropical rain-forest in southwest Amazonia, 1992 to 1993. Science 270, 778-780.

Gu, L., Shugart, H.H., Fuentes, J.D., Black, T.A., Shewchuk, S.R., 1999. Micrometeorology, biophysical exchanges and NEE decomposition in a two-story boreal forest - development and test of an integrated model. Agric. Forest Meteorol. 94, 123-148.

Gu, L., Baldocchi, D.D., Verma, S.B., Black, T.A., Vesala, T., Falge, E.M., Dowty, P.R., 2002. Advantages of diffuse radiation for terrestrial ecosystem productivity. J. Geophys. Res., 107(D6), DOI 10.1029/2001JD001242.

Gu, L., Post, W.M., King, A.W., 2004. Fast labile carbon turnover obscures sensitivity of heterotrophic respiration from soil to temperature: a model analysis. Global Biogeochem. Cycles, 18, Gb1022, DOI 10.1029/2003gb002119.

Harazono, Y., Miyata, A., Ohta, N., Oechel, W.C., 2000. Greenhouse gas fluxes at Arctic tundra ecosystem in winter and thawing period. In: Proceedings of the 24th Conference on Agricultural and Forest Meteorology, American Meteorological Society, August 14-18, 2000. Davis, CA, USA, pp. 193-194.

Jarvis, P.G., Massheder, J.M., Hale, S.E., Moncrieff, J.B., Rayment, M., Scott, S.L., 1997. Seasonal variation of carbon dioxide, water vapor, and energy exchanges of a boreal black spruce forest. J. Geophys. Res. Atmospheres 102 (D24), 28953-28966.

Lee, X., 1998. On micrometeorological observations of surface-air exchange over tall vegetation. Agric. Forest Meteorol. 91, 39-49.

Massman, W.J., Lee, X., 2002. Eddy covariance flux corrections and uncertainties in long-term studies of carbon and energy exchanges. Agric. Forest Meteorol. 113 (1-4), 121-144.
Massman, W.J., Sommerfeld, R.A., Mosier, A.R., Zeller, K.F., Hehn, T.J., Rochelle, S.G., 1997. A model investigation of turbulencedriven pressure-pumping effects on the rate of diffusion of $\mathrm{CO}_{2}$, $\mathrm{N}_{2} \mathrm{O}$, and $\mathrm{CH}_{4}$ through layered snowpacks. J. Geophys. Res. Atmospheres 102, 18851-18863.

Rogie, J.D., Kerrick, D.M., Sorey, M.L., Chiodini, G., Galloway, D.L., 2001. Dynamics of carbon dioxide emission at Mammoth Mountain, California. Earth Planet. Sci. Lett. 188, 535541.

Saleska, S.R., Miller, S.D., Matross, D.M., Goulden, M.L., Wofsy, S.C., da Rocha, H.R., de Camargo, P.B., Crill, P., Daube, B.C., de Freitas, H.C., Hutyra, L., Keller, M., Kirchhoff, V., Menton, M., Munger, J.W., Pyle, E.H., Rice, A.H., Silva, H., 2003. Carbon in Amazon forests: unexpected seasonal fluxes and disturbanceinduced losses. Science 302, 1554-1557.

Staebler, R.M., Fitzjarrald, D.R., 2004. Observing subcanopy $\mathrm{CO}_{2}$ advection. Agric. Forest Meteorol. 122, 139-156.

Suyker, A.E., Verma, S.B., 2001. Year-round observations of the net ecosystem exchange of carbon dioxide in a native tallgrass prairie. Global Change Biol. 7, 279-289.

Tang, J.W., Baldocchi, D.D., Qi, Y., Xu, L.K., 2003. Assessing soil $\mathrm{CO}_{2}$ efflux using continuous measurements of $\mathrm{CO}_{2}$ profiles in soils with small solid-state sensors. Agric. Forest Meteorol. 118 (3-4), 207-220.

Valentini, R., Matteucci, G., Dolman, A.J., Schulze, E.D., Rebmann, C., Moors, E.J., Granier, A., Gross, P., Jensen, N.O., Pilegaard, K., Lindroth, A., Grelle, A., Bernhofer, C., Grunwald, T., Aubinet, M., Ceulemans, R., Kowalski, A.S., Vesala, T., Rannik, U., Berbigier, P., Loustau, D., Guomundsson, J., Thorgeirsson, H., Ibrom, A., Morgenstern, K., Clement, R., Moncrieff, J., Montagnani, L., Minerbi, S., Jarvis, P.G., 2000. Respiration as the main determinant of carbon balance in European forests. Nature 404, 861-865.

Vesala, T., Haataja, J., Aalto, P., Altimir, N., Buzorius, G., Garam, E., Hämeri, K., Ilvesniemi, H., Jokinen, V., Keronen, P., Lahti, T., Markkanen, T., Mäkelä, J.M., Nikinmaa, E., Palmroth, S., Palva, L., Pohja, T., Pumpanen, J., Rannik, Ü., Siivola, E., Ylitalo, H., Hari, P., Kulmala, M., 1998. Long-term field measurements of atmosphere-surface interactions in boreal forest combining forest ecology, micrometeorology, aerosol physics and atmospheric chemistry. Trends Heat Mass Momentum Transfer 4, 17-35.

Wofsy, S.C., Goulden, M.L., Munger, J.W., Fan, S.-M., Bakwin, P.S., Daube, B.C., Bassow, S.L., Bazzaz, F.A., 1993. Net exchange of $\mathrm{CO}_{2}$ in a mid-latitude forest. Science 260, 13141317.

Xu, L.K., Baldocchi, D.D., 2003. Seasonal trends in photosynthetic parameters and stomatal conductance of blue oak (Quercus douglasii) under prolonged summer drought and high temperature. Tree Physiol. 23, 865-877.

Xu, L.K., Baldocchi, D.D., 2004. Seasonal variation in carbon dioxide exchange over a Mediterranean annual grassland in California. Agric. Forest Meteorol. 123, 79-96. 